\title{
Article/Artigo
}

\section{Comparison of capture methods for the diagnosis of adult anopheline populations from State of Mato Grosso, Brazil}

\author{
Comparação de métodos de captura para o diagnóstico da população de anofelinos adultos \\ do Estado de Mato Grosso
}

Nanci Akemi Missawa ${ }^{1,3 \dagger}$, Ana Lúcia Maria Ribeiro ${ }^{1,2}$, Giovana Belem Moreira Lima Maciel ${ }^{3}$ and Peter Zeilhofer ${ }^{4}$

\begin{abstract}
Introduction: The present study compares human landing catches of primary malaria vectors with two alternative methods of capture: the Shannon trap and the Mosquito magnet. Methods: This study used regression models to adjust capture data to a negative binominal distribution. Results: Capture numbers and relative percentages obtained from the three methods vary strongly between species. The highest overall captures were obtained for Anopheles triannulatus with captures for the Shannon trap and the Mosquito magnet measuring more than $330 \%$ higher than captures obtained by human landings. For Anopheles darlingi, captures by the Shannon trap and the Mosquito magnet were about $14 \%$ and $26 \%$ of human landing catches, respectively. Another species with malaria transmission potential that was not sampled by human landing captures weascaptured by the Shannon trap and the Mosquito magnet (Anopheles oswaldoi). Both alternative sampling techniques can predict the human landing of Anopheles triannulatus, but without proportionality. Models for Anopheles darlingi counts, after totaling daily captures, are significant and proportional, but prediction models are more reliable when using the Shannon trap compared with the Mosquito magnet captures. Conclusions: These alternative capture methods can be partially recommended for the substitution of human landing captures or, at least, as complementary forms of monitoring for malarial mosquitoes.
\end{abstract}

Keywords: Anopheles. Capture methods. Shannon trap. Mosquito magnet. Human landing. Mato Grosso.

\section{RESUMO}

Introdução: $\mathrm{O}$ presente estudo compara a captura através da isca humana dos principais vetores da malária, com dois métodos alternativos de captura, a armadilha luminosa de Shannon e a armadilha Mosquito magnet. Métodos: O presente estudo utiliza modelos de regressão para ajustar os dados obtidos para uma distribuição binomial negativa. Resultados: Os números e as proporções relativas obtidas nos três métodos variaram fortemente entre as espécies. A maior densidade capturada foi de Anopheles triannulatus, através das armadilhas de Shannon e do Mosquito magnet sendo mais de 330\% superior que a obtida pela captura por isca humana. Para Anopheles darlingi, capturas com a armadilha de Shannon e com o Mosquito magnet representaram cerca de 14\% e 26\%, respectivamente, em comparação com a captura através da isca humana. Outras espécies com potencial de transmissão da malária não foram capturadas com a utilização da isca humana, mas foram coletadas na armadilha de Shannon e no Mosquito magnet (Anopheles oswaldoi). Ambas as técnicas alternativas de captura, podem predizer significativamente a captura através da isca humana de Anopheles triannulatus, porém sem proporcionalidade. Os números previstos para o Anopheles darlingi, após a contagem total da captura diária, são significativos e proporcionais, mas a previsão é mais confiável para a armadilha de Shannon que para o Mosquito magnet. Conclusões: A comparação de métodos alternativos de captura pode ser parcialmente recomendada para a substituição da captura através da isca humana ou, pelo menos, como uma forma complementar de coleta de mosquitos.

Palavras-chaves: Anopheles. Métodos de captura. Armadilha de Shannon. Mosquito magnet. Isca humana. Mato Grosso.

\footnotetext{
1. Faculdade de Ciências Médicas, Universidade Federal de Mato Grosso, Cuiabá, MT. 2. Hospital Universitário Julio Muller, Ministério da Saúde, Cuiabá, MT. 3. Laboratório de Entomologia, Secretaria de Estado de Saúde de Mato Grosso, Cuiabá, MT. 4. Departamento de Geografia, Universidade Federal de Mato Grosso, Cuiabá, MT. †In memoriam.

Address to: Me Giovana Belem Moreira Lima Maciel. Lab. Entomologia/SES/MT. Av. Adauto Botelho s/no, Parque da Saúde, Bairro Coophema, 78085-200 Cuiabá, MT, Brasil.

Phone: 5565 3661-2934

e-mail: giovanabio@terra.com.br; anadarlingi@yahoo.com.br

Received in 29/10/2010
}

Accepted in 19/04/2011

\section{INTRODUCTION}

Mosquito sampling is a requirement for malaria vector population studies and, therefore, is an important component in malaria disease control. A reduction in the malaria incidence in the Amazon of about $45 \%$ between 2000 and 2002 and the decrease in high-risk municipalities from 160 to 76 were both partially attributed to an improvement in and the decentralization of entomological surveys ${ }^{1}$. However, the reduction in areas of social instability, including areas with mining, migration and irregular occupation have also led to an eventual improvement in the treatment of the disease.

Transmission of the four Plasmodium species (P. vivax, P. falciparum, P. malariae and P. ovale) that cause malaria in Central Western Brazil is realized exclusively by hematophagous females of the Anopheles genus (Diptera: Culicidae) ${ }^{2}$. These mosquitoes have an Anopheles (Nyssorhynchus) darlingi Root, 1926, have been the most anthropophilic species, responsible for the majority of malaria transmission. Other vectors with secondary importance for transmission are Anopheles (Nyssorhynchus) oswaldoi (Peryassú, 1922), Anopheles (Nyssorhynchus) triannulatus

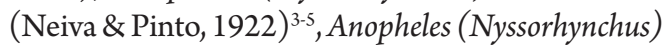
albitarsis Lynch-Arribálzaga, $1878^{2,5}$ and Anopheles (Nyssorhynchus) nuneztovari Gabaldón, $1940^{2}$.

Count results, as well as achievable spatial and temporal coverage of epidemiological studies of anopheline populations are heavily influenced by sampling methods. Currently, the collection of malaria mosquitoes landing on human baits is considered to be the most representative method for determining human landing activity because female mosquitoes are subsequently collected as they attempt to feed on the human collectors ${ }^{6}$. Frequent reports of malaria transmission to collectors, even in regions with low prevalence, have led to in serious ethical considerations and reduce the readiness of technicians in health organizations to apply these techniques ${ }^{7}$. 
In addition, the all-night collection method is labor intensive and imposes bias because of variation in the host-attractiveness of human collectors $^{8,9}$. Under the financial and human resources available, achievable temporal and spatial coverage is limited, particularly for the surveillance of a territory with continental dimensions, such as Brazil. Furthermore, the use of alternative traps allows for standardizing the attractant, thereby improving the comparability of capture results ${ }^{10}$.

The efficiency levels of alternative captures methods for malaria transmitting anopheline species, however, have exhibited varying results ${ }^{11}$. It has been widely recognized that both light and odorbaited traps result in inferior counts of $A$. darlingi than do human landing captures ${ }^{12-15}$, but there are no systematic studies available for the transitional forest region in the Southern Amazon. Thus, it is not known if alternative capture techniques can be applied to reliably predict human landing catches.

In this context, the Shannon trap and the Mosquito magnet were evaluated for extra-domiciliary sampling in a malaria endemic area in Central Brazil. We used generalized linear regressions based on a negative binominal distribution to adjust the catching data.

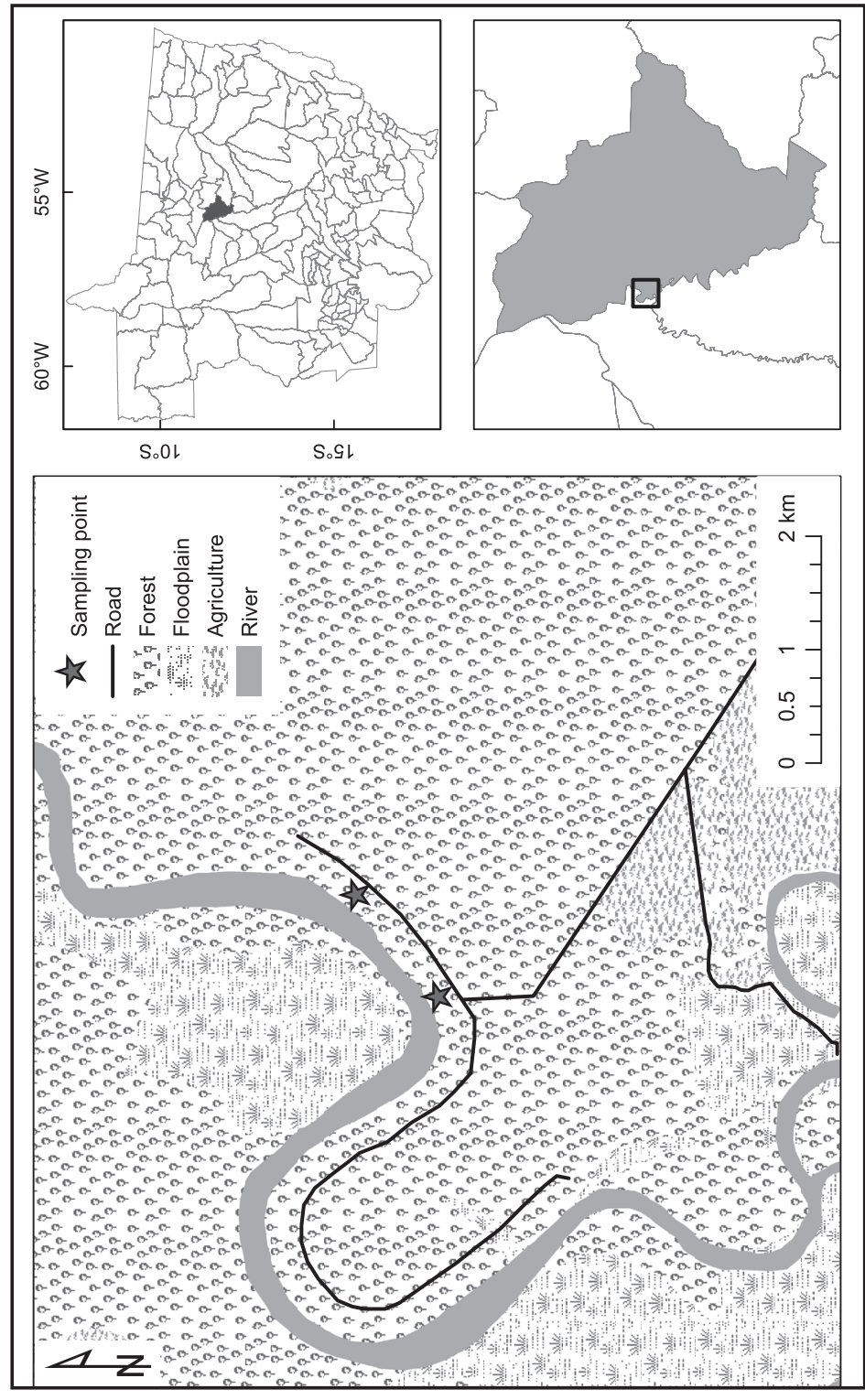

FIGURE 1 - Mosquito sampling sites in the Sinop municipality, State of Mato Grosso Brazil.

\section{METHODS}

Capture campaigns were performed at two rural locations in the municipality of Sinop, which is located in the Central Northern region of the State Mato Grosso, Central Brazil. The sites were located alongside the Teles Pires River inside semi-decidual riparian stands of the transitional forest ecotones at latitude S11041'27,1" and W55 $42^{\prime} 48,9^{\prime \prime}$ and S1 $1^{\circ} 41^{\prime} 47,1^{\prime \prime}$ and W55 $42^{\prime} 75,6^{\prime \prime}$, respectively, at an altitude of approximately $380 \mathrm{~m}$ (Figure 1).

Sampling locations were about $30 \mathrm{~km}$ from the urban area of Sinop and were, therefore, distant from a potential focus of urban malaria. Neither study area had ever been treated with insecticides.

In the present study, human landing (HL) collections of the anopheline species were compared with two alternative entomologic sampling techniques: the Mosquito magnet (Defender Model, American Biophysics Corp, East Greenwich RI) (MM) and a white cotton Shannon trap (ST).

In both sampling locations, the three capture methods were implanted at a distance of $100 \mathrm{~m}$ in opposing directions from farm

domiciles to avoid interference among the experiments. One person was responsible for every catching method. To limit bias, capturers alternated their sampling method after one hour of the experiment. A total of 48 sampling campaigns ( $252 \mathrm{hs}$ of capture) were conducted bimonthly between 2007 and 2008 during three- and four-day campaigns during the rainy season and three campaigns during the dry season. Samplings were conducted without interruption between the hours of 17:00 and 24:00.

Human landing collection techniques followed protocol $34^{6}$. The malaria transmission risk to researchers during an entomological field survey can be considered low because no malaria case has been reported for the study area. The ST had a dimension of $1.7 \mathrm{~m} \mathrm{x} 1.4 \mathrm{~m} \times 1.4 \mathrm{~m}$ and was constructed with a white cloth. White light and a protected collector were used as the primary attractions. Specimens were removed hourly using a manual aspirator. The MM (Mosquito Magnet ${ }^{\text {Tx }}$ model MM4100) uses a counter flow technology to capture insects. Propane gas is catalytically converted into carbon dioxide $\left(\mathrm{CO}_{2}\right)$, heat, and moisture to simulate a human presence. Voucher specimens were then taken to the laboratory of entomology at the Federal University of Mato Grosso.

Relevant findings in entomological studies are represented by count data, such as the non-negative integer number of specimens captured. The comparison of capture results through pair wise statistical tests are commonly performed after logarithmic transformation of the count data, which demands the addition of one to zero counts. Smith ${ }^{16}$, however, pointed out that this procedure may produce misleading results and that regression models may be more appropriate for comparing capture results ${ }^{11,17}$.

The random sampling of a homogeneous population of mosquitoes is expected to result in a Poisson distribution of counts. In addition to this random sampling variation, mosquito counts vary as a result of differences in underlying densities and, therefore, the observed variance in recorded mosquito numbers is typically greater than the mean (over dispersion) ${ }^{11}$, particularly if there are elevated numbers of zero-counts ${ }^{18}$. Therefore, count data were fitted to a two-parameter, negative 
binomial distribution ${ }^{19}$. Captures were intended to be generated from an underlying distribution of densities by taking a distinct value for each matched set of capture methods. The second parameter was used to adjust for the variance independent of the mean. For the regression adjustment, we applied the Generalized Linear Model module of the SPSS 17 statistical software package and used a negative binomial model with a log link.

Model performance was evaluated by I) the deviance, which is defined as two times the difference of the log-likelihood for the maximum achievable model (i.e., each subject's response serves as a unique estimate of the negative binomial parameter) and the log likelihood under the fit model; II) standard error of the regression coefficients and the Wald 95\% confidence limits calculated as an estimate $\pm(\mathrm{z} \alpha / 2)^{*}$ (Standard Error) where $\mathrm{z} \alpha / 2$ is a critical value from the standard normal distribution; and III) chi-Square and p-values for testing the null hypothesis that an individual predictor's regression coefficient is zero if the rest of the predictors are in the model ${ }^{20}$.

\section{RESULTS}

Species captured by one or more methods included Anopheles (Anopheles) benarrochi Galbadón, Cova \& Lopes, 1941, A. darlingi, A. (Anopheles) mediopunctatus (Theobald, 1903), A. (Anopheles) nigritarsis (Chagas, 1907), A. oswaldoi, A. (Anopheles) peryassui Dyar \& Knab, 1908, A. (Nyssorhynchus) Galbadón, Cova-Garcia \& Lopes, 1940 and A. triannulatus; three of them (bold) are potential malaria vectors in Brazil, resulting in a total of 906 (HB), 2678 (MM) and 2812 (ST) individuals, respectively (Table 1).

Anopheles triannulatus was by far the most frequently captured species, representing $87 \%(\mathrm{HB}), 98 \%(\mathrm{MM})$ and $97 \%(\mathrm{ST})$ of all captured individuals. Captures for A. triannulatus were 334\% and 348\% of HL catches for MM and ST, respectively. Relative capture frequency of $A$. darlingi, the principal malaria vector in Brazil, exhibited more variation between the compared methods and was much higher for HL captures (10\%) than for MM (0.005\%) and ST captures $(0.009 \%)$. This result corresponds to relative capture rates of $14 \%(\mathrm{MM})$ and $26 \%$ (ST) of HL catches. A. oswaldoi, a species relevant for malaria transmission in the Amazon region according several authors ${ }^{19,21}$, was
TABLE 1 - Total numbers of anopheline mosquitoes caught using matched Human landing, Mosquito magnet and Shannon trap catch methods (April 2007 through February 2008). Bold species are known malaria vectors. Human landing Mosquito magnet Shannon trap (HL) (MM) (ST)

\begin{tabular}{lrlr}
\hline Anopheles benarrochi & 2 & 10 & 1 \\
\hline Anopheles darlingi & 91 & $13^{*}$ & $24^{*}$ \\
\hline Anopheles mediopunctatus & 23 & $10^{* *}$ & 29 \\
\hline Anopheles nigritarsis & 2 & 0 & 0 \\
\hline Anopheles oswaldoi & 0 & 9 & 10 \\
\hline Anopheles peryassui & 0 & 1 & 0 \\
\hline Anopheles rangeli & 0 & 3 & 7 \\
\hline Anopheles triannulatus & 788 & $2,632^{*}$ & $2,741^{*}$ \\
\hline Total & $\mathbf{9 0 6}$ & $\mathbf{2 , 6 7 8}$ & $\mathbf{2 , 8 1 2}$ \\
\hline
\end{tabular}

*highly significant model $(\mathrm{p}<0.001),{ }^{* *}$ significant model $(\mathrm{p}<0.05)$.

captured at almost equal rates by the $\mathrm{MM}$ and $\mathrm{ST}$. The relative capture rates of A. mediopunctatus, a species not considered relevant for malaria transmission, were lower for MM than for ST captures, representing $43 \%$ and $126 \%$ of HL catches, respectively.

Temporal inter-day capture patterns for the three methods were similar for A. triannulatus with an expressive peak at dusk (18-19 pm) (Figure 2). Only ST captures varied less throughout the sampling periods with a slight decrease during the following hours. Capture curves for $A$. darlingi revealed a slight hematophagic activity cycle during the early evening hours ${ }^{22}$ for HL and MM sampling. Average maximum capture rates for ST were delayed. Results, however, were influenced by the low density of the species during most sampling campaigns. The peak HL captures between 22:00 and 23:00 originated from a single sampling day during the rainy season in which eight specimens were captured.

Differences in absolute numbers obtained from MM and ST captures do not independently invalidate these alternative catching techniques for the prediction of HL densities. If catch numbers for each capture technique are proportional to each other, it can be assumed that similar fractions of the mosquito population are captured, and HL can be predicted by simple linear models.

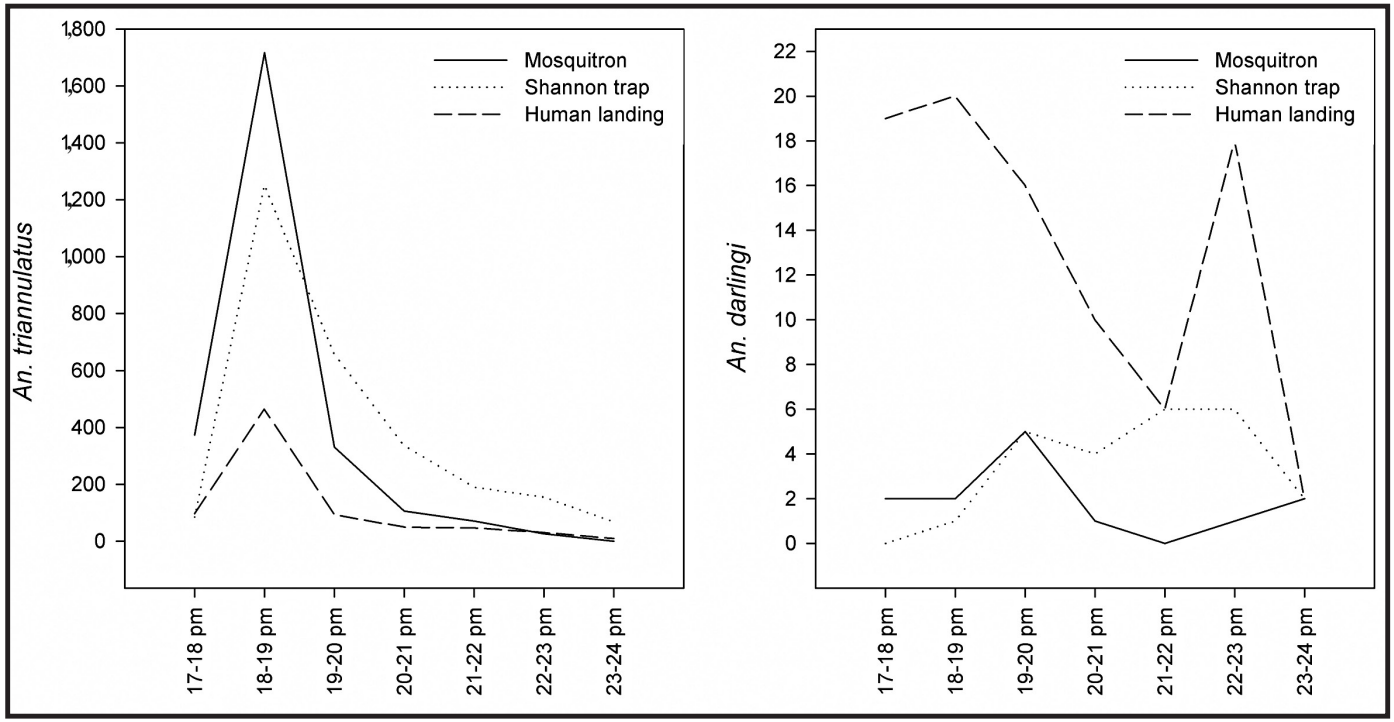

FIGURE 2 - Inter-day curves for total captures of matched Mosquito magnet, Shannon trap and Human landing catches (April 2007 through February 2008) for Anopheles triannulatus and Anopheles darlingi. 
If each hourly capture period is used as a sample, highly significant negative binomial $(\mathrm{NB})$ regression models $(\mathrm{p}<0.001)$ are obtained for $A$. triannulatus for both capture methods. The scatters of ST and MM catches against the matched HL catches suggest, however, that there is considerable variation within the fit relationships for the two trapping methods (Figure 3) and that there is no proportionality between the captures (coefficient intervals not including 1); both methods underestimate HL in most cases, particularly for higher catch numbers using ST. The limited performances of the models of both capture methods are reflected in the deviances of 544.51 and 339.84 and standard errors of 0.0195 and 0.0155 , respectively. For A. triannulatus, MM catches were slightly better fit to HL than to ST captures.

At only $4.8 \%$ of the hourly MM captures and $6.7 \%$ of ST captures, specimens of $A$. darlingi were caught, whereas this accounted for $16.3 \%$ for HL captures. If an intercept is included, the NB regression model identifies a highly significant coefficient for ST captures $(\mathrm{p}<0.001)$ and a significant one for MM captures $(\mathrm{p}<0.025)$. Negative binomial regression performance is slightly better for ST, but both models must be considered notably poor due to coefficient standard errors of 0.25 and 0.44 , respectively, and Wald chi-square values for B of only 21.56 and 5.03, respectively.

In both capture methods, HL counts of $A$. darlingi were proportional, but the model performance and the prediction of nonzero cases was poor (Figure 3 ). Because catch numbers were much lower, a catch with ST statistically corresponds to higher catches of two specimens with HL.

As seen in the average hourly captures, catches for A. darlingi did not coincide temporally. If the daily captures are summarized, regression models for both alternative capture methods were strongly improved (Figure 4).

The performance of the ST captures was superior to that obtained for $\mathrm{MM}$ catches, resulting in coefficient standard errors of 0.16 vs. 0.27 and Wald chi-square values for B of 23.57 vs. 18.07, respectively. In the case of ST captures, the model revealed proportionality; however, in the case of MM captures, it was only due to the high standard error (0.37). In contrast to A. darlingi, models for A. triannulatus did not improve for both alternative capture techniques if captures were summarized (not shown).
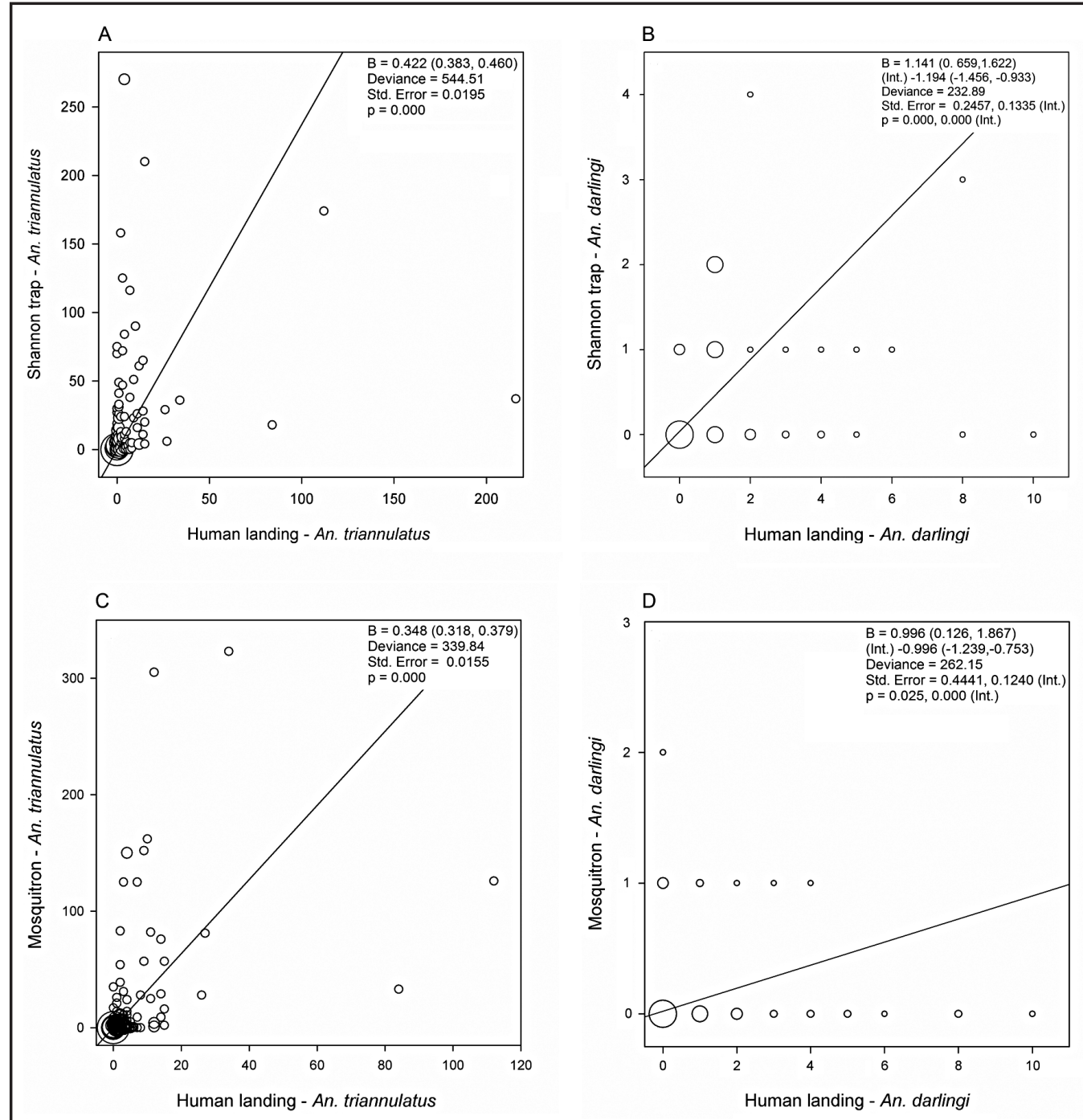

FIGURE 3 - Numbers of anopheline mosquitoes caught using Shannon trap (A, B) and Mosquito magnet collection methods (C, D) versus those caught with matched outdoor Human landing catches. Lines show the negative binomial regression models. 


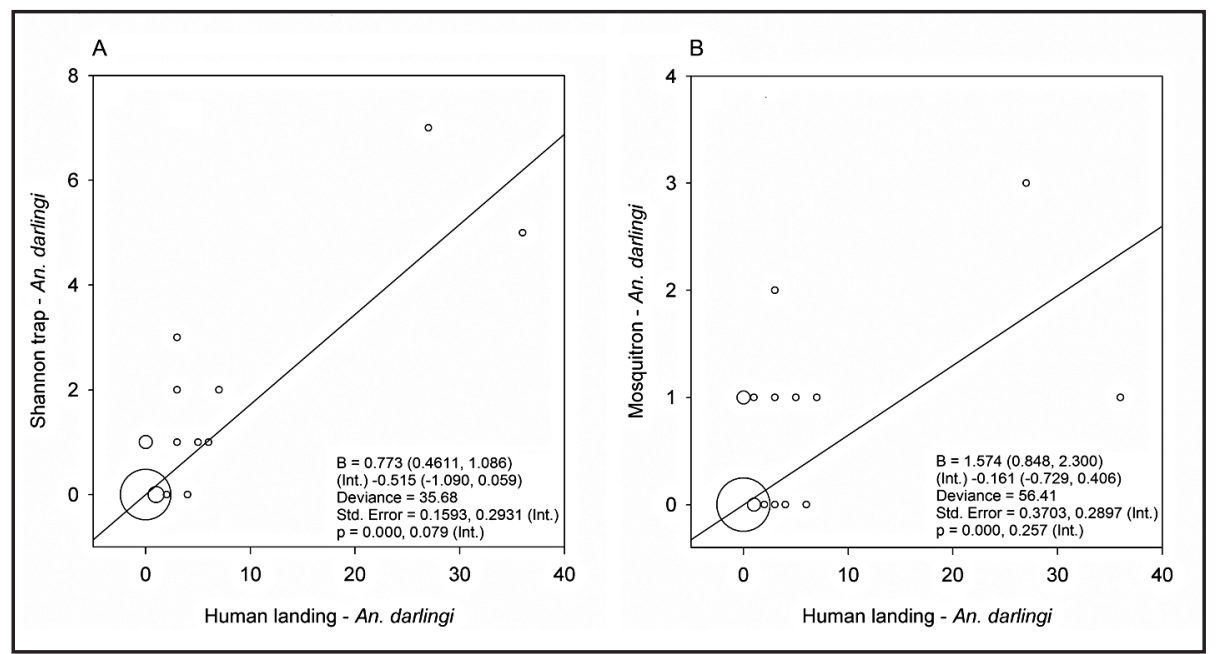

FIGURE 4 - Numbers of Anopheles darlingi caught with Shannon trap (A) and Mosquito magnet (B) collection methods versus those caught with matched outdoor Human landing catches. Lines show the negative binomial regression models.

\section{DISCUSSION}

Captured species, their counts, the relative proportions obtained from the three methods and the predictability of HL catches varied strongly between species.

Similar to a study by Dusfour et $\mathrm{al}^{15}$, the MM captures demonstrated the highest species richness, with six species in total collected versus five for ST and four for HL. Counts of A. triannulatus were more than three times higher for ST and MM than those obtained by HL captures. In contrast, both alternative methods were less sensitive than HL catches. This finding is likely the result of two factors. First, high mosquito densities, mainly observed during the rainy season, exceed the catch capacity of a capturer applying the HL method. Second, attraction in HL captures is reduced by the presence of other mammals in the study area (cattle, apes), and A. triannulatus is known to be less anthropophilic than A. darlingi ${ }^{23,24}$.

Other captured species with the potential for malaria transmission, such as A. oswaldoi, are exophilic and zoophilic species that are suspected to be involved in malaria transmission in the Amazon ${ }^{21}$ but were rarely caught or were not caught using one of the compared methods. As a result, we were unable to make a conclusion regarding capture efficiency for these species.

Despite these differences in absolute values, significant NB regression models can be adjusted for pairs of hourly capture results. Both capture techniques have a similar performance in predicting $\mathrm{HL}$ captures of $A$. triannulatus. None of the alternative methods can predict HL counts using a linear model.

Hourly A. darlingi counts were reasonably well predicted by ST, but the model performance for MM captures was poor. Proportionality was obtained, and models were strongly improved if hourly captures were summarized per daily catching period for ST and at lower levels for MM. We believe this finding is related to the low absolute densities of the species in the study area and their anthropophilic feeding behavior. Many zero counts in the hourly capture periods biased the model adjustment. When compared to $\mathrm{HL}$ catches, maximum ST captures were delayed by 2 to $3 \mathrm{~h}$. After an exogenous stimulus (crepuscule), females feed first and subsequently appear to use ST for resting ${ }^{18}$.
From these data, the compared alternative capture methods can be partially recommended to substitute for the HL capture method. The ST method is superior to the MM method, particularly for the prediction of $A$. darlingi. These results are encouraging principally because proportionality between the methods was obtained. $\mathrm{MM}$ can be seen, at least, as a complementary form for mosquito surveillance. Because MM is a passive method that requires only simple installation and maintenance, it is particularly useful for improving the temporal and spatial coverage of malaria vector surveillance when faced with a limited budget and ethical concerns. For the monitoring of malaria vectors in the region, HL catches should remain the standard reference method for verifying and calibrating new sampling methods.

\section{ACKNOWLEDGMENTS}

We wish to thank the technicians of the Laboratório de Entomologia of Secretaria de Estado de Saúde de Mato Grosso and the Secretaria Municipal de Saúde de Sinop for their contributions in the field and laboratory activities that were essential for the development of this work. We also thank the reviewers' thoughtful and constructive comments, which helped to improve the paper.

\section{CONFLICT OF INTEREST}

The authors declare that there is no conflict of interest.

\section{FINANCIAL SUPPORT}

This study was supported by Fundação de Amparo à Pesquisa do Estado de Mato Grosso (FAPEMAT), Conselho Nacional de Desenvolvimento Científico e Tecnológico (CNPq) e Secretaria de Estado de Saúde de Mato Grosso (SES-MT).

\section{REFERENCES}

1. Ministério da Saúde. Programa Nacional de Prevenção e Controle da Malária. Brasília: Secretaria de Vigilância em Saúde; 2003.

2. Marcondes CB. Entomologia Médica e Veterinária. São Paulo: Editora Atheneu; 2001 
3. Branquinho MS, Lagos CTB, Rocha RM, Natal D, Barata LMS, Cochrane AH, et al. Anophelines in the state of Acre, Brazil, infected with Plasmodium falciparum, $P$. vivax, the variant $P$. vivax VK247 and P. malariae. Trans R Soc Trop Med Hyg 1993; 87:391-394.

4. Deane LM. Malaria vectors in Brazil. Mem Inst Oswaldo Cruz 1986; 81:5-14.

5. Klein TA, Lima JBP, Tada MS. Comparative susceptibility of anopheline mosquitoes to Plasmodium falciparum in Rondonia, Brazil. Amer J Trop Med Hyg 1991; 44:598-603.

6. Carreri-Bruno GC, Ciaravolo RMC, Pereira M. Malária adquirida durante atividade entomológica na Serra do Mar, região Sudeste do Brasil. Rev Saude Publica 1995; 29:142-143.

7. World Health Organization. Malaria entomology and vector control. WHO/ CDS/CPE/SMT; 2003.

8. Lindsay S, Adiamah JH, Miller JE, Pleas RJ, Amstrong JRM. Variation in attractiveness of humans subjects to malaria mosquitoes (Diptera: Culicidae) in The Gambia. J Med Entomol 1993; 30:368-373.

9. Knols BGJ, Mboera LE, Takken W. Eletric nets for studying odour-mediated host-seeking behavior of mosquitoes. Med Vet Entomol 1998; 12:116-120.

10. Schmied W, Takken W, Killeen G, Knols B, Smallegange R. Evaluation of two counterflow traps for testing behaviour-mediating compounds for the malaria vector Anopheles gambiae s.s. under semi-field conditions in Tanzania. Malar J 2008; 7:230.

11. Hii JLK, Smith T, Mai A, Ibam E, Alpers MP. Comparison between anopheline mosquitoes (Diptera: Culicidae) caught using different methods in a malaria endemic area of Papua New Guinea. Bull Entomol Res 2000; 90: 211-219.

12. Rubio-Palis Y. Evaluation of light traps combined with carbon dioxide and 1-octen-3-ol to collect anophelines in Venezuela. J Am Mosq Control Assoc 1996; 12:91-96.

13. Rubio-Palis Y, Guzmán H, Magris M. Evaluación de la eficiencia de trampas de luz vs cebo humano para capturar Anopheles darlingi Root. Bol Dir Malariol San Amb 1999; 39:30-32.

14. Santos F, Lima JBP, Braga IA. Comparison of four methods for collecting adult anophelines mosquitoes from malaria endemic area in Rondonia, Brazil. En Mosquito Vector Control and Biology in Latin America. A Tenth Symposium. J Am Mosq Control Assoc 2000; 16:295-312.

15. Dusfour I, Carinci R, Gaborit J, Issaly J, Girod R. Evaluation of Four Methods for Colleting Malaria Vectors in French Guiana.J Econ Entomol 2010; 103:973-976.

16. Smith T. Proportionality between light trap catches and landing densities of malaria vectors. J Am Mosq Control Assoc 1995; 11:377-378.

17. Mathenge EM, Misiani GO, Oulo DO, Irungu LW, Ndegwa PN, Smith TA, et al. Comparative performance of the Mbita trap, CDC light trap and the human landing catch in the sampling of Anopheles arabiensis, An. funestus and culicine species in a rice irrigation in western Kenya. Malar J 2005; 4:7.

18. Govella JN, Chaki PP, Geissbuhler Y, Kannady K, Okumu F, Charlwood JD, et al. A new tent trap for sampling exophagic and endophagic members of the Anopheles gambiae complex. Malar J 2009; 8:157.

19. Branquinho MS, Araújo MS, Natal D, Marelli MT, Rocha RM, Taveira FAL, et al. Anopheles oswaldoi an important potential malaria vector in Acre, Brazil. Trans R Soc Trop Med Hyg 1996; 90:233.

20. Venables WN, Ripley BD. Modern applied statistics with S-Plus. New York: Springer-Verlag; 1994.

21. Marrelli MT, Honorio NA, Flores-Mendoza C, Lourenço-de-Oliveira R, Marinotti O, Kloetzel JK. Comparative susceptibility of two members of the Anopheles oswaldoi complex, An. oswaldoi and An. konderi, to infection by Plasmodium vivax. Trans R Soc Trop Med Hyg 1999; 93:381-384.

22. Guimarães EG, Mello RP, Lopes CM, Alencar J, Gentile C. Prevalência de anofelinos (Diptera: Culicidae) no crepúsculo vespertino em áreas da Usina Hidrelétrica de Itaipu, no município de Guaíra, Estado do Paraná, Brasil. Mem Inst Oswaldo Cruz 1997; 92:745-754.

23. Turell MJ, Sardelis MR, Jones JW, Watts DM, Fernandez R, Carbajal F, et al. Seasonal distribution, biology, and human attraction patterns of mosquitoes (Diptera: Culicidae) in a rural village and adjacent forested site near Iquitos, Peru. J Med Entomol 2008; 45:1165-1172.

24. Suarez-Mutis MC, Fe NF, Alecrim W, Coura JR. Night and crepuscular mosquitoes and risk of vector-borne diseases in areas of piassaba extraction in the middle Negro River basin, state of Amazonas, Brazil. Mem Inst Oswaldo Cruz 2009; 104:11-17. 